Gut, 1986, 27, 913-918

\title{
Intestinal fluid and electrolyte transport in man during reduced circulating blood volume
}

\author{
H SJÖVALL, H ABRAHAMSSON, G WESTLANDER, R GILLBERG, S REDFORS, \\ M JODAL, AND O LUNDGREN
}

From the Department of Physiology, University of Göteborg and Division of Gastroenterology, Department of Medicine II, Sahlgrens Hospital, Göteborg, Sweden

SUMmARY The effect on intestinal net transport of fluid and electrolytes of a reduced circulating blood volume was studied in the human jejunum with the triple lumen perfusion technique. The blood volume was reduced by changing the lower extremities from an elevated to a dependent position combined with a venous stasis. The tilting manoeuvre, probably resembling a bleeding of about $600-800 \mathrm{ml}$, significantly increased net absorption of fluid, sodium and chloride while glucose transport was unaffected. Concomitantly the blood flow decreased and vascular resistance increased in the forearm vascular bed. The results are consistent with the hypothesis that activity in the sympathetic nervous system initiated from unloading of the cardiopulmonary volume receptors enhances intestinal absorption of fluid and electrolytes. The results also indicate that the human intestines are an important target organ in the compensatory mechanisms activated during hypovolaemia due to - for example, haemorrhage.

Recent investigations on the control of intestinal fluid and electrolyte transport suggest an important role for nerves in transport control both during physiological and pathophysiological circumstances. The pathophysiological studies have been devoted to investigations of various secretory states in the small intestine such as the fluid losses evoked by cholera toxin, ${ }^{1}$ by the heat stable enterotoxin of Escherichia coli, ${ }^{2}$ and by bile salts. ${ }^{3}$ These studies suggest that activation of local nervous reflexes may play an important role in the pathogenesis of several different types of secretion in vivo.

In addition to these local nervous pathways, the small intestine is also supplied with extrinsic adrenergic fibres of sympathetic origin. The effects of adrenergic agonists on intestinal transport have been fairly extensively studied with the Ussing chamber technique. ${ }^{45}$ These studies have revealed that $\alpha$-adrenergic agonists decrease short circuit current by decreasing electrogenic anion secretion (bicarbonate and/or chloride secretion). Concomitantly, there is an increase in electroneutral sodium and chloride uptake as revealed by radioactive tracer studies. A similar response is also elicited by release of tissue noradrenaline with tyramine. ${ }^{4}$

Address for correspondence: Dr Ove Lundgren, Department of Physiology, University of Göteborg, Box 33031, S-400 33 Göteborg, Sweden.

Received for publication 12 November 1985
Comparatively few attempts have been made to study the effects of sympathetic nerve activation in vivo. ${ }^{5}$ Stimulation of the regional sympathetic fibres in the cat increases jejunal net fluid and sodium absorption primarily by an inhibition of the tissue to lumen flux of electrolytes. ${ }^{6-8}$ These findings are in line with the old observation made by Bernard ${ }^{9}$ and by Florey $e t \mathrm{al}^{10}$ that severing the sympathetic fibres evoked, with a certain time lag, an intestinal net fluid secretion. Furthermore, the sympathetic effect seemed to be dependent on nervous activity of the intramural secretory reflexes mentioned above that is, the sympathetic nerve fibres seem to modulate secretory neurones with small or no effect on the absorptive cells themselves. ${ }^{11} 12$

In the cat the sympathetic nervous outflow to the gut controlling fluid transport has been shown to be reflexly regulated by input from cardiovascular high and low pressure receptors. ${ }^{13} 14$ Furthermore, haemorrhage increases intestinal electrolyte and fluid absorption, an effect which is abolished by sympathetic denervation of the segment. ${ }^{15}$ The present study was started as an attempt to elucidate if the findings made on animals could also be reproduced in man. To this end we investigated the fluid and electrolyte transport in human subjects using a non-absorbable tracer technique (polyethylene glycol). Fluid and electrolyte transport was 
studied before, during and after tilting the subjects in combination with a venous occlusion of the lower extremities, a procedure which mimics bleeding by withdrawing a rather large blood volume from the central circulation. ${ }^{16}$

\section{Methods}

SUBJECTS

Seven healthy volunteers, all men, were studied (median age 41 years, range 27-47). All had given their informed consent. The study was evaluated and accepted by the ethical committee of the University of Göteborg. None of the subjects had a history of gastrointestinal disease or abused drugs or alcohol.

\section{MEASUREMENT OF FLUID AND ELECTROLYTE}

TRANSPORT

The perfusion technique described by Fordtran $e t$ $a l^{17}$ was used. In short, after fasting overnight subjects were intubated with a triple lumen polyvinyl tube prepared by fusing single tubes (internal diameter $2 \mathrm{~mm}$ ) with glue. One of the tubes was radio-opaque and an intestinal biopsy instrument was coupled to the end of the tube. The mixing segment was $10 \mathrm{~cm}$ and the test segment $30 \mathrm{~cm}$. The location of the tube was determined fluoroscopically and the site of infusion was placed $10-30 \mathrm{~cm}$ below the ligament of Treitz. The rate of perfusion was maintained at about $12 \mathrm{ml} / \mathrm{min}$ with a constant flow pump (Harvard model 500-1200). The perfusate contained $(\mathrm{mM}): \mathrm{NaCl} 106 ; \mathrm{NaHCO}_{3} 25 ; \mathrm{KCl} 4$; glucose 30. Polyethylene glycol (PEG; molecular weight $4000 \mathrm{~d} ; 2 \mathrm{~g} / \mathrm{l}$ ) was also added to the solution. Fluid was collected manually by gentle suction from the two distal openings at a rate of approximately $1.5 \mathrm{ml} / \mathrm{min}$.

After an equilibration period of $\mathbf{4 0}$ minutes three test periods of 30 minutes each were carried out. The second and third test periods were preceded by a 10 minute equilibration period. Measurements of PEG, glucose, sodium, and chloride concentrations were carried out on the perfusate and the aspirated fluid. Polyethylene glycol was determined with the turbidimetric method according to Hydén, ${ }^{18}$ glucose with an enzymatic method (Gluco-Perid, Boehringer-Mannheim), sodium concentration with a Eppendorf flame photometer and chloride ions with a Corning Eel 920 Chloride meter. Net fluid uptake as well as net transport rates of glucose, sodium and chloride were determined with standard equations. ${ }^{17}$
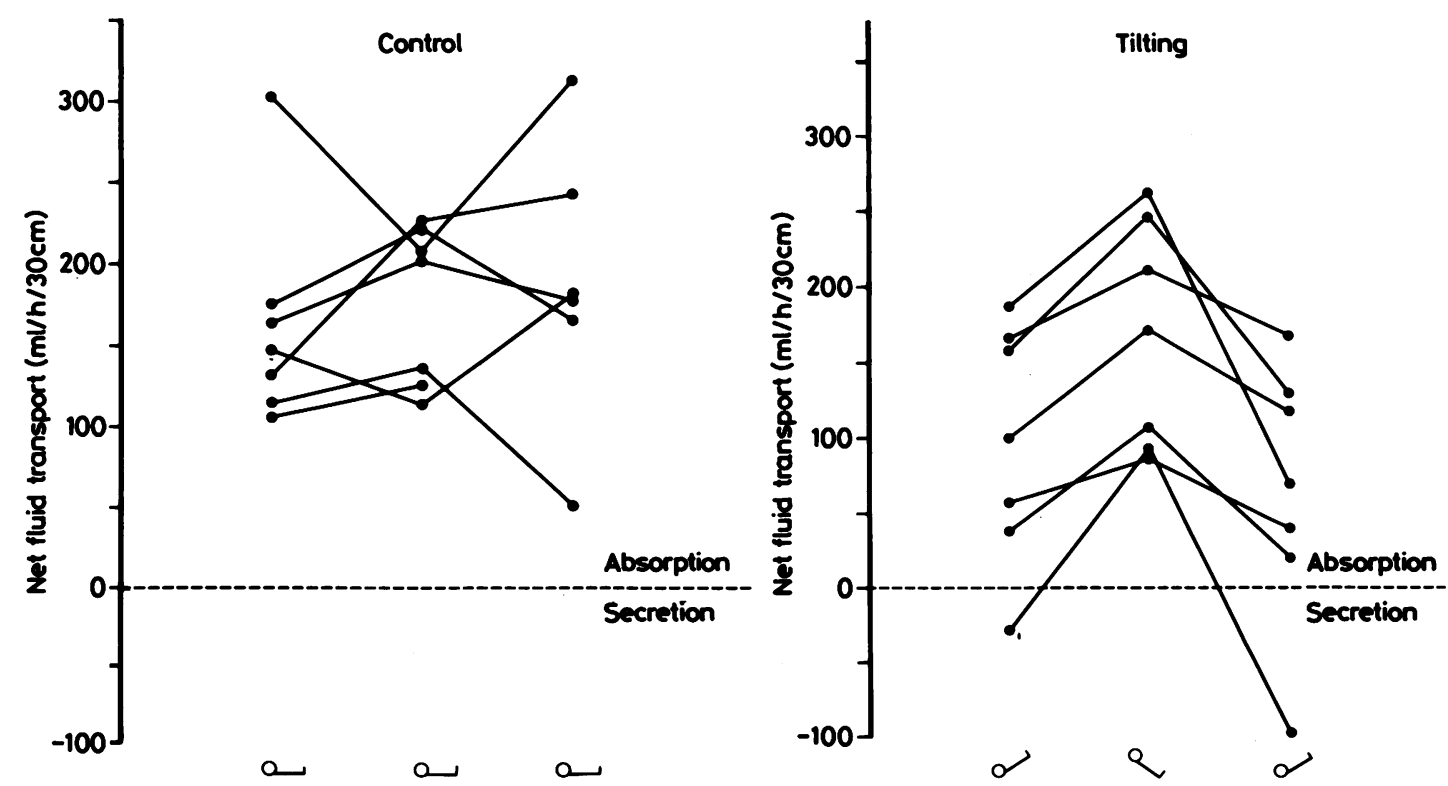

Fig. 1 Effect on intestinal net fluid transport seen in the two experimental series done in the study. The left panel shows the individual data from the control experiments, the right panel gives the corresponding values for the series in which the effect of tilting combined with venous stasis of the lower extremities was studied. The positions of the body in the different experimental periods are shown at the bottom of the panels. 
MEASUREMENTS OF CARDIOVASCULAR

PARAMETERS

Arterial pressure was measured at the heart level pressure was calculated as diastolic pressure plus one third of pulse pressure. Blood flow in the forearm (mainly skeletal muscle blood flow) was measured with a strain gauge mercury plethysmograph. During measurements the hand circulation was excluded by means of a cuff inflated to $250 \mathrm{mmHg}$. Flow values presented represent a mean value of three consecutive measurements. Flow resistance was calculated by dividing perfusion pressure with blood flow.

\section{EXPERIMENTAL PROTOCOL}

Two series of experiments were done. In one series $(n=7)$, measurements during three consecutive control periods of 30 minutes were undertaken with the subjects in a horizontal position. No blood flow measurements were made in these experiments.

In the second series $(n=7)$ the legs of the subjects were elevated about $30^{\circ}$ above the horizontal level during the first $\mathbf{3 0}$ minutes. The second period was done with legs in a downward position. Furthermore, a venous stasis of about $50 \mathrm{mmHg}$ was applied to the thighs with tourniquets. These two procedures presumably pooled blood in the lower extremities. A second series of control measurements were performed after releasing the venous stasis and raising the legs to the position used in the first control period. Care was taken to maintain the trunk in the same position throughout the experiments.

\section{STATISTICS}

Statistical significance was tested using the sign test

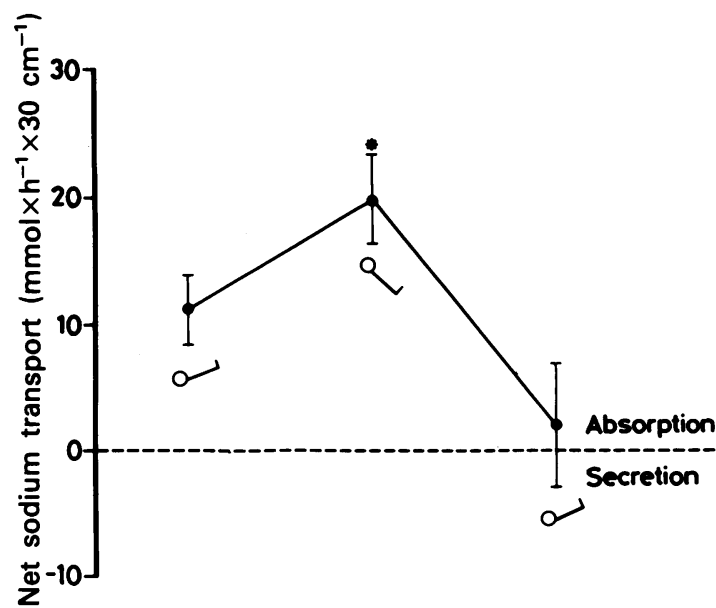
according to the Riva Rocci method. Mean arterial

and Wilcoxon's signed rank test. ${ }^{19}$ When comparing blood flow measurements Student's $t$ test was used as the flow measurements represented mean values of several registrations. A probability of 0.05 or less was considered to be statistically significant.

\section{Results}

In the first series of experiments the subjects were in a horizontal position throughout the observation periods. Seven subjects were investigated and all the measured intestinal transport variables studied remained unaltered during the three $\mathbf{3 0}$ minute test periods, although there was a slight tendency for fluid and electrolyte transport to increase with time (Fig. 1, left panel, Table 1). Blood pressure and

Table 1 Intestinal fluid and electrolyte transport in control subjects during three consecutive observations periods.

Mean $\pm S E, n=7$.

\begin{tabular}{lrrr}
\hline & Period 1 & Period 2 & Period 3 \\
\hline $\begin{array}{l}\text { Net fluid absorption, } \\
\text { ml } \times \mathrm{h}^{-1} \times 30 \mathrm{~cm}^{-1}\end{array}$ & $164 \pm 25$ & $178 \pm 18$ & $190 \pm 35$ \\
$\begin{array}{c}\text { Net sodium absorption, } \\
\text { mmol } \times \mathrm{h}^{-1} \times 30 \mathrm{~cm}^{-1}\end{array}$ & $17.5 \pm 4.4$ & $22.1 \pm 3.6$ & $21.5 \pm 3.8$ \\
$\begin{array}{c}\text { Net chloride absorption, } \\
\text { mmol } \times \mathrm{h}^{-1} \times 30 \mathrm{~cm}^{-1}\end{array}$ & $13.0 \pm 3.0$ & $14.9 \pm 2.9$ & $16.0 \pm 3.8$ \\
\hline
\end{tabular}

Table 2 Intestinal net glucose uptake $\left(\mathrm{mmol} \times \mathrm{h}^{-1} \times 30 \mathrm{~cm}^{-1}\right)$ in the two experimental series of thisstudy. Mean $\pm S E n=7$.

\begin{tabular}{llll}
\hline & Period 1 & Period 2 & Period 3 \\
\hline Control series & $6 \cdot 2 \pm 0.9$ & $4.9 \pm 0.9$ & $5 \cdot 5 \pm 0.8$ \\
Tilting & $6 \cdot 7 \pm 0.5$ & $7 \cdot 2 \pm 0.9$ & $6 \cdot 5 \pm 0.9$ \\
\hline
\end{tabular}

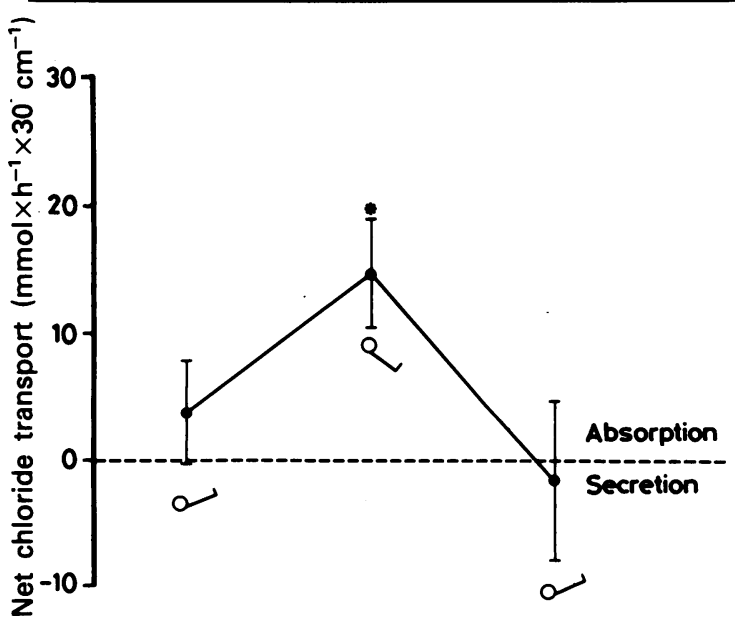

Fig. 2 Effect on intestinal net sodium (left panel) and chloride (right panel) transport of tilting combined with venous stasis of the lower extremities. Bars denote $S E n=7$. Asterisk denotes statistical significance from control $(p<0.05)$. 
heart rate did not change during the course of these experiments (data not shown). No blood flow measurements were made.

The results of the second series of experiments, investigating the effect of blood pooling in the lower extremities on the fluid and electrolyte transport, are shown in Figure 1 (right panel) and Figure 2. In the first control period of these experiments the net fluid absorption amounted to $97 \pm 30 \mathrm{ml} \times \mathrm{h}^{-1} \times$ $30 \mathrm{~cm}^{-1}$, a value not significantly different from the control values in the first series. During the tilting manoeuvre in the second registration period the fluid absorption rate significantly increased to $168 \pm 28 \mathrm{ml}^{2} \times \mathrm{h}^{-1} \times 30 \mathrm{~cm}^{-1}$. In the second control period the fluid absorption returned to a value not significantly different from that of the first control period $\left(64 \pm 33 \mathrm{ml} \times \mathrm{h}^{-1} \times 30 \mathrm{~cm}^{-1}\right)$. The transport of electrolytes changed in parallel to the variations in net fluid absorption (Fig. 2). With regard to the absorption of glucose no effect on rate of transport was seen (Table 2). The measured blood flow in the forearm skeletal muscles decreased during the middle observation period. Because arterial pressure stayed rather constant, the flow reduction reflected an increased flow resistance in the studied muscle region (Table 3).

\section{Discussion}

In the present study we mimicked a blood loss in human subjects by reducing the circulating blood volume. The procedure used was similar to that used by Mellander and Öberg ${ }^{16}$ who estimated that the volume withdrawn was $600-800 \mathrm{ml}$ - that is, about $15 \%$ of the estimated total blood volume. The transport of fluid and electrolytes was followed in the small intestine. It was shown that such a reduction in circulating blood volume markedly increased the rates of fluid, sodium, and chloride absorption. Concomitantly, a vasoconstriction was

Table 3 Calculated mean arterial pressure, heart rate, forearm blood flow and flow resistance during control conditions (periods 1 and 3) and during tilting (period 2).

\begin{tabular}{|c|c|c|c|c|}
\hline & Period 1 & Period 2 & Period 3 & $n$ \\
\hline \multicolumn{5}{|l|}{ Mean arterial pressure, } \\
\hline Pulse pressure, $\mathrm{mmHg}$ & $41 \pm 3$ & $40 \pm 4$ & $49 \pm 3$ & 7 \\
\hline Heart rate/min & $60 \pm 5$ & $61 \pm 4$ & $63 \pm 5$ & 7 \\
\hline $\begin{array}{l}\text { Forearm blood flow, } \\
\mathrm{ml} \times \mathrm{min}^{-1} \times 100 \mathrm{~g}\end{array}$ & $2 \cdot 8 \pm 1 \cdot 1$ & $1.6 \pm 0 \cdot 5^{*}$ & $2.8 \pm 0.8$ & 4 \\
\hline \multicolumn{5}{|c|}{$\begin{array}{l}\text { Forearm flow resistance, } \\
\quad \mathrm{mmHg} \times \min \times 100 \mathrm{~g} \times \mathrm{ml}^{-1} 50.4 \pm 14.8 \quad 77.9 \pm 25.0 * 45 \cdot 1 \pm 13.64\end{array}$} \\
\hline
\end{tabular}

recorded in the forearm muscles, indicating that the experimental manoeuvre had elicited vascular reflexes, presumably via an activation of the sympathetic nervous system (see below).

The reflex mechanism underlying the observed transport changes is not possible to elucidate in detail from the present observations. Studies on animals and man, however, strongly suggest that the two receptor stations most likely to sense a moderate redistribution of blood volume are the high pressure receptors in the carotid sinus and the aortic arch, ${ }^{20}$ and the cardiopulmonary volume receptors with vagal afferents. ${ }^{21}$ In man, the high pressure baroreceptors seem to be mainly involved in the reflex control of heart rate and in the control of the splanchnic circulation, ${ }^{22}$ whereas the low pressure cardiopulmonary receptors are of major importance in the reflex regulation of muscle blood flow. The finding that the effects on the intestine occurred without any measurable effects on mean arterial pressure, pulse pressure or heart rate speak against the possibility that this response was mediated by the arterial baroreceptors. On the other hand, the finding that a clearcut forearm vasoconstriction was elicited without any concomitant effects on pressure parameters may indicate that the model used leads to a fairly selective unloading of cardiac low pressure afferents. The present experiments, hence, indirectly support that these latter receptors may be involved in the reflex regulation of jejunal fluid transport.

The efferent part of the reflex adjustment elicited in the present experiments was not studied in any detail, but, again, it is possible to draw some conclusions from other human and animal studies. It is well established from such studies that a bleeding of similar magnitude as mimicked in the present study evokes complex adjustments of the nervous and hormonal control of body functions. There is an increased rate of firing in the sympathetic fibres ${ }^{23}$ and a release of certain hormones such as angiotensin and antidiuretic hormone. ${ }^{24}$ An increased firing in adrenergic nerves and an increased release of angiotensin augment rates of fluid and electrolyte transport in experimental animals. ${ }^{825}$ The action of angiotensin may be secondary to its facilitating effect on release of noradrenaline from sympathetic fibres. ${ }^{2526}$ The role of antidiuretic hormones in the control of intestinal fluid transport is less well established. The net effect of haemorrhage on fluid and electrolyte transport, however, is an increased rate of absorption. The results of the present study suggest that similar adjustments also occur in man.

To summarise, the present results may be taken to indicate that the increased rate of fluid and electrolyte absorption seen when reducing the circulating 
blood volume in man is mediated via the sympathetic nervous system via a unloading of cardiopulmonary 'volume receptors'. In this context the observations made by Johnson $e a^{22}$ are interesting. They showed that the vasoconstriction seen in the splanchnic organs was small (less than $10 \%$ of control) when unloading the cardiopulmonary receptors by lower body negative pressure. Thus, the reflex response elicited from the low pressure cardiovascular receptors upon bleeding may differ with regard to the effects on vascular smooth muscle and fluid transport in the splanchnic area.

The net fluid absorption during the control period in the 'tilting' experiments was somewhat lower than that registered in the experimental series with the legs in the horizontal position. This may indicate that the elevation of the legs in the tilting experiments reduced the intestinal fluid absorption. The difference between the two control values, however, were not statistically significant, the observed difference being caused by one high and one low value in respective series (see Fig. 1).

It is interesting to note that the effects on jejunal transport during tilting were seen only on fluid and electrolyte transport whereas net glucose transport rate was not significantly affected. These findings agree with the effects seen in cats during electrical stimulation of the splanchnic nerves. ${ }^{12}$ Such experiments have indicated that the sympathetic effect is probably exerted by the inhibition of an active chloride secretion from the intestinal crypts. Also, the fact that rate of glucose uptake was constant before, during, and after tilting argues against the possibility that the transport effects seen in the present study were caused by some entirely passive mechanism such as changes in body position. If the variations in fluid and electrolyte transport were due to such artefacts one would have expected glucose absorption to vary in the same way as - for example, sodium.

It is possible from the present results to calculate the rate of fluid absorption that could occur from the whole small intestine during optimal conditions. The results of Figure 1 indicate that fluid uptake per hour increases $60-70 \mathrm{ml}$ in a $30 \mathrm{~cm}$ long intestinal segment upon tilting. Extrapolating this finding to the full length of the small intestine (3-4 m) suggests that the increased rate of absorption would correspond to a fluid volume of $600-900 \mathrm{ml} / \mathrm{hour}$. If fluid absorption had been negligible before bleeding the maximal rate of absorption recorded in Figure 1 corresponds to a mobilisation of $1600-2100 \mathrm{ml} /$ hour. These values should be compared with the transcapillary flux of fluid from extravascular to intravascular space seen in skeletal muscle in the acute phase of haemorrhage. Mellander and Öberg ${ }^{16}$ estimated that $150-175 \mathrm{ml}$ could be mobilised by this 'autotransfusion' during the first 10 minutes of the simulated bleeding in a $75 \mathrm{~kg}$ man. This mechanism is, in contrast with intestinal fluid absorption self limiting, because the absorption of a largely protein free solution from the interstitial space will by necessity reduce the plasma colloid osmotic pressure gradient across the capillary wall and eventually eliminate the net force driving fluid into the capillaries. The potential rate of intestinal fluid absorption is of such a magnitude that it may be of interest to use the small intestine as a route of fluid replacement in certain clinical circumstances.

This study was supported by grants from the Swedish Medical Research Council (2855), Astra Research Foundation, Swedish Society for Medical Sciences, Medical Society of Göteborg, The Medical Research Council of the Swedish Life Insurance Companies and by The Faculty of Medicine, University of Göteborg.

\section{References}

1 Cassuto J, Jodal M, Tuttle R, Lundgren $\mathrm{O}$. On the role of intramural nerves in the pathogenesis of cholera toxin-induced intestinal secretion. Scand J Gastroenterol 1981; 16: 377-84.

2 Eklund S, Jodal $M$, Lundgren $\mathrm{O}$. The enteric nervous system participates in the secretory response to the heat stable enterotoxins of Escherichia coli in rats and cats. Neuroscience 1985; 14: 673-81.

3 Karlström L, Cassuto J, Jodal M, Lundgren O. The importance of the enteric nervous system for the bilesalt-induced secretion in the small intestine of the rat. Scand J Gastroenterol 1983; 18: 117-23.

4 Tapper EJ. Local modulation of intestinal ion transport by enteric neurons. Am J Physiol 1983; 244: G457-68.

5 Hubel KA. Neuronal regulation of ion transport. In: Skadhauge E, Heintze K, eds. Intestinal absorption and secretion. Falk Symposium 36. Lancaster, MTP Press, 1984: 67-82.

6 Brunsson I, Eklund S, Jodal M, Lundgren O, Sjövall $H$. The effect of vasodilatation and sympathetic nerve activation on net water absorption in the cat's small intestine. Acta Physiol Scand 1979; 106: 61-8.

7 Sjövall H, Redfors S, Hallbäck DA et al. The effect of splanchnic nerve stimulation on blood flow distribution, villous tissue osmolality and fluid and electrolyte transport in the small intestine of the cat. Acta Physiol Scand 1983; 117: 359-65.

8 Sjövall $\mathrm{H}$. Sympathetic control of jejunal fluid and electrolyte transport. An experimental study in cats and rats. Acta Physol Scand 1984; suppl 535: 1-63.

9 Bernhard C. Lecons sur les liquides de l'organisme. Paris: Balliére, 1859. 
10 Wright RD, Jennings MA, Florey HW, Lium R. The influence of nerves and drugs on secretion by the small intestine and an investigation of the enzymes in intestinal juice. $Q J$ Exp Physiol 1940; 30: 73-120.

11 Sjövall $H$, Redfors S, Jodal M, Lundgren O. On the mode of action of the sympathetic fibres on intestinal fluid transport: evidence for the existence of a glucosestimulated secretory nervous pathway in the intestinal wall. Acta Physiol Scand 1983; 119: 39-48.

12 Sjövall $\mathbf{H}$, Jodal $M$, Lundgren $\mathrm{O}$. Further evidence for a glucose-activated secretory mechanism in the jejunum of the cat. Acta Physiol Scand 1984; 120: 437-43.

13 Sjövall H, Jodal M, Redfors S, Lundgren O. The effect of carotid occlusion on the rate of net fluid absorption in the small intestine of rats and cats. Acta Physiol Scand 1982; 115: 447-53.

14 Sjövall H, Redfors S, Biber B, Martner J, Winsö O. Evidence for cardiac volume receptor regulation of feline jejunal blood flow and fluid transport. Am J Physiol 1984; 246: G401-10.

15 Redfors $S$, Sjövall $H$. The importance of nervous and humoral factors in the control of vascular resistance, blood flow distribution and net fluid absorption in the cat small intestine during hemorrhage. Acta Physiol Scand 1984; 121: 211-22.

16 Mellander S, Öberg B. Transcapillary fluid absorption and other vascular reactions in the human forearm during reduction of the circulating blood volume. Acta Physiol Scand 1967; 71: 37-46.

17 Cooper H, Levitan R, Fordtan JS, Ingelfinger FJ. A method for studying absorption of water and solute from the human small intestine. Gastroenterology 1966; 50: 1-7.

18 Hydén S. A turbidimetric method for the determination of higher polyethylene glycols in biological materials. Ann $R$ Agr Coll 1955; 22: 139-45.

19 Siegel S. Nonparametric statistics for the behavioral sciences. Tokyo: McGraw Hill Kogakusha, Ltd. 1956.

20 Mancia G, Mark AL. Arterial baroreflexes in humans. In: Handbook of physiology, Sect 2 The cardiovascular system. 1983; III: 755-94.

21 Mark AL, Mancia G. Cardiopulmonary baroreflexes in humans. In: Handbook of physiology. Sect 2 The cardiovascular system. 1983; III: 795-814.

22 Johnson JM, Rowell LB, Niederberg M, Eisman MM. Human splanchnic and forearm vasoconstrictor responses to reductions of right atrial and aortic pressures. Circ Res 1974; 34: 515-24.

23 Lundgren $O$, Lundvall $J$, Mellander S. Range of sympathetic discharge and reflex vascular adjustments in skeletal muscle during hemorrhagic hypotension. Acta Physiol Scand 1964; 62: 380-90.

24 Ganong WF. Review of medical physiology. Los Altos, California: Lange Med Publ, 1983.

25 Levens NR, Munday KA, Parsons BJ, Poat JA, Steward CP. Noradrenaline as a possible mediator of the actions of angiotensin on fluid transport by rat jejunum in vivo. J Physiol 1979; 286: 351-60.

26 Levens NR. Modulation of jejunal ion and water absorption by endogenous angiotensin after hemorrhage. Am J Physiol 1984; 246: G634-43. 